\title{
Effectiveness of Reminiscence Therapy on the Level of Depression among elderly Adult patients Admitted in Selected Hospital Chennai
}

\author{
V. Hemavathy ${ }^{1}$, Rengila.$S^{2}$ \\ Principal, Sree Balaji College of Nursing, Bharat University, Chennai, India \\ II nd Year M.Sc Nursing, Sree Balaji College of Nursing, Bharat University, Chennai, India
}

\begin{abstract}
Background of the Study: Old age is considered as the second childhood period where an elderly react like a child. depression is an common psychiatric problem in the old age that is often misdiagnosed and untreated. Objectives: To assess the level of depression among elderly adults. Evaluate the effectiveness of reminiscence therapy on level of depression among elderly adults. Find association between levels of depression with selected demographic variables in elderly adults. Hypothesis: There will be significant difference between the pre- and post-test scores in the level of depression among elderly patients. Methodology: Pre experimental one group pre-test and post-test design was selected for this study. Purposive sampling technique was used for the study. Final Result and Conclusion: In the pre test the level of depression among selected 30 samples 2(6.7\%) Of them had mild depression and 23(76.6\%) of them had moderate depression and 5(16.7\%) had severe depression. In the post test level of depression 3(10\%) are normal 18(60\%) of them had mild depression and 9(30\% had moderate depression. The effectiveness of reminiscence therapy on depression among elderly using paired " $t$ " test shows 8.1 significant at the level of $P<0.05$ Which implying that there was significant decrease in the level of depression in the post test.
\end{abstract}

Keywords: Depression, effectiveness, Reminiscence therapy, elderly, hospital.

\section{Introduction}

Growing old is a characteristics feature of all living beings. . The difficult changes that many especially elderly or older adults face most of time lead to depression. However depression is not a normal part of aging .depression in older adults is associated with poor health. reminiscence therapy considered an alternative intervention for treating depression in older adults. The WHO (2008) Report states that globally the percentage over the age of 60 years is estimated to be $6.5 \%$. By 2030 , the world population, aged 65 years, is projected to increase approximately to 973 million, increase from $6.5 \%$ to $12 \%$ and among them $8.5 \%$ had psychiatric problems.

\subsection{Objectives}

- To assess the level of depression among elderly adults.

- To evaluate the effectiveness of reminiscence therapy on level of depression among elderly adults.

- To find the association between level of depression with selected demographic variables in elderly adults.

\subsection{Hypothesis}

H1: There will be significant difference between the preand post-test scores in the level of depression among elderly patients

$\mathrm{H} 2$ : There will be significant association between the level of depression and selected demographic variables.

\section{Methodology}

Pre -experimental one group pre-test and post-test design was selected for this study in Sree Balaji Medical College and Hospital, Chennai. The study population will comprise of elderly adults in the age group of (50-70) years. Total sample size 30 both male and female elderly patients are selected for the study by Purposive sampling technique. The questionnaire has 2 parts consisting of Demographic variables these are age sex, marital status, religion, domicile ,degree of physical dependence, education, source of income. in the second part of questionnaire modified geriatric depression scale(short form) consisting of 15 items was used. Interpretation of score was done as follow

\begin{tabular}{|c|c|}
\hline Cateoory & Score \\
\hline Normol & $0-4$ \\
\hline Normal & $0-4$ \\
\hline Mild & $5-8$ \\
\hline Moderate & $9-11$ \\
\hline Severe & $12-15$ \\
\hline
\end{tabular}

\section{Result}

Table 2: Pre test level of Depression

\begin{tabular}{|l|c|c|}
\hline \multicolumn{1}{|c|}{$\begin{array}{c}\text { Pretest Level of } \\
\text { Depression }\end{array}$} & \multicolumn{2}{|c|}{ Pre-Test } \\
\cline { 2 - 3 } & No & Percentage (\%) \\
\hline Normal & - & - \\
\hline Mild depression & 2 & 6.7 \\
\hline Moderate depression & 23 & 76.7 \\
\hline severe depression & 5 & 16.6 \\
\hline Total & 30 & 100 \\
\hline
\end{tabular}

Reveals that among 30 samples $2(6.7 \%)$ of them had mild level of depression , 23( $76.7 \%)$ had moderate level of depression and $5(16.6 \%)$ of them had severe level of depression in the pre test.

\section{Volume 4 Issue 12, December 2015}




\section{International Journal of Science and Research (IJSR) \\ ISSN (Online): 2319-7064}

Index Copernicus Value (2013): 6.14 | Impact Factor (2014): 5.611

Table 3: post test level of depression among elderly adult patients

\begin{tabular}{|c|c|c|}
\hline \multirow{2}{*}{$\begin{array}{c}\text { Posttest Level of } \\
\text { Depression }\end{array}$} & \multicolumn{2}{|c|}{ Post-Test } \\
\cline { 2 - 3 } & No & Percentage (\%) \\
\hline Normal & 3 & 10 \\
\hline Mild depression & 18 & 60 \\
\hline Moderate depression & 9 & 30 \\
\hline severe depression & - & - \\
\hline Total & 30 & 100 \\
\hline
\end{tabular}

Table 4: comparison of pre test and post test Level of Depression among Elderly Adult Patients

\begin{tabular}{|c|c|c|c|c|c|}
\hline \multirow{2}{*}{ Level of Depression } & \multicolumn{2}{|c|}{ Pre-Test } & \multicolumn{2}{|c|}{ Post-Test } & Chi- \\
\cline { 2 - 5 } & No & Percentage & No & Percentage & square \\
\hline Normal & - & - & 3 & 10 & \\
\hline Mild depression & 2 & 6.7 & 18 & 60 & \multirow{3}{T}{$\mathrm{T}=8.1$} \\
\hline Moderate depression & 23 & 76.7 & 9 & 30 & \\
\hline severe depression & 5 & 16.6 & - & - & $\mathrm{P}<0.05$ \\
\hline Total & 30 & 100 & 30 & 100 & \\
\hline
\end{tabular}

Reveals the comparison of Reminiscence therapy among depression .It shows that $6.7 \%$ of them had mild level of depression, $76.7 \%$ had moderate level of depression and $16.6 \%$ of them had severe level of depression in the pre test . $10 \%$ were normal, $60 \%$ had mild depression and $30 \%$ had moderate depression in the post test. the effectiveness of reminiscence therapy among elderly the depression mean score was 10 in the pre -test, SD was 1.5 and mean post test score was 7 and SD was 1.7 , so the total overall value reduction was 3 and SD was -0.2 with the paired t- test value is 8.1 and there is significant effectiveness at $\mathrm{P}$ value is 2.05 $<0.05$.

\section{Major Findings of the Study}

Regarding the demographic variables in the age group (30\%) of the samples were in the age group of 50-55 years , (40\%) of the samples were in the age group of 56-60 years , $(23.3 \%)$ of the samples were in the age group of 61-65 years and $(6.6 \%)$ of the samples were in the age group of $66-70$ years . regarding the sex status $(53.3 \%)$ were males and $(47 \%)$ were females and which majority of them were married with the ratio of $(93.3 \%)$ and unmarried was $(6.6 \%)$ on this majority were Hindus with $(60 \%)$ Christians were $(23.3 \%)$ and Muslims were (16.6\%) patient haling from urban area $(47 \%)$ and those from rural area were $(53.3 \%)$.regarding the degree of physical dependence the independent patient ratio is $(86.7 \%)$ when compared to dependent patient ratio which is $(13.3 \%)$.regarding the educational status the illiterate people ratio is ( $23.3 \%)$ and those with primary education is $(20 \%)$ secondary education is $(30 \%)$ higher education is $(16.6 \%)$ and graduate are $(10 \%)$. regarding the source of income the patient who are not working have an high percentage of $(66.7 \%)$ when compared to working group who were $(20 \%)$ and pensioners $(13.3 \%)$

In the pre test the level of depression among selected 30 samples $2(6.7 \%)$ Of them had mild depression and $23(76.6 \%)$ of them had moderate depression and $5(16.7 \%)$ had severe depression .In the post test level of depression among selected 30 samples $3(10 \%)$ are normal $18(60 \%)$ of them had mild depression and $9(30 \%$ had moderate depression.

\section{Conclusion}

The study reveals that there was significant decrease in the level of depression among elderly in the post test. The effectiveness of reminiscence therapy on depression among elderly using paired " $t$ " test shows 8.1 significant at the level of $\mathrm{P}<0.05$

\section{References}

[1] Brunner and Suddarth's healthcare of the older adult. Medical surgical nursing. $9^{\text {th }}$ ed. Philadelphia: Lippincott Company; 2000.

[2] Sharma OP. Geriatric care: A textbook of geriatrics and gerontology. $3^{\text {rd }}$ ed. New Delhi: Sanat Printers; 2008.

[3] Sharma PO, Handa V. A guide to elderly care. New Delhi: Green Park; 2009.

[4] Lai CKY, Irischi, Kayser-Jones J. A randomized controlled trial of a specific reminiscence approach to promote the well- being of nursing home residents with dementia. International Psycho Geriatrics 2004 Sep;33(1):33-49.

[5] Cappeliez, P., \& Robitaille, A. (2010). Coping mediates the relationships between reminiscence and psychological well-being among older adults. Aging \& Mental Health, 14(7), 807-818.

[6] Anderson AJ. Treatment of depression in older adults. International Journal of Psychosocial Rehabilitation 2002 Jan;32(6):69-78.

[7] www.pubmed.com

[8] www.medlineplus.com

[9] www.medsafe.com 